\title{
The Effect of Pre-operative Obstructive Sleep Apnea (OSA) Severity on the Change of Sleep Patterns in Children Undergoing Adenotonsillectomy
}

\author{
Belgin Tutar ${ }^{1}$ • Muhammed Enis Ekincioğlu ${ }^{1}$ - Güler Berkiten ${ }^{1}$ • Pınar Yılmazbaş ${ }^{2}$. Semih Karaketir ${ }^{1}$. \\ Melis Ece Arkan ${ }^{1} \cdot$ Ziya Saltürk $^{1} \cdot$ Ayşe Enise Göker ${ }^{1}$. Yavuz Uyar ${ }^{1}$
}

Received: 21 January 2020 / Accepted: 30 March 2020 /Published online: 27 April 2020

(C) Dr. K C Chaudhuri Foundation 2020

To the Editor: Obstructive sleep apnea (OSA) is defined as snoring, apnea-hypopnea associated sleep deprivation, oxygen desaturation and possible hypercapnia due to total or partial obstruction of the upper airways [1]. Adenotonsillar (AT) hypertrophy is the most important cause of obstructive sleep apnea (OSA) in childhood [2]. The presence of untreated OSA may lead to learning disabilities, behavioral problems, cardiovascular disorders and growth retardation in children. Therefore, it is a serious condition that can greatly affect the future lives of children [3-5].

The study included 50 children, aged 4-11 y old between December 2018 and April 2019. Patients with pathologies other than adenotonsillar hypertrophy were excluded. Fifty children with OSA were included in the study due to adenotonsillar hypertrophy of grade 2 and above. The diagnoses of adenotonsillar hypertrophy were made by nasopharyngeal endoscopic and oropharyngeal examination estimated choanal obstruction (for adenoid size) and Tonsil grading system offered by Friedman et al. (for tonsil size). The parents of all the patients completed the Pediatric Sleep Questionnaire (PSQ) and Children's Sleep Habits Questionnaire (CSHQ) preoperatively. Three months after the operations, they were re-evaluated with the CSHQ. Ethical approval of the study was obtained from the local ethic committee.

A significant difference was found in all the questions and total scores except for delay in falling asleep in the pre- and 3mo post-operative comparison of CSHQ responses from all

Belgin Tutar

belgintutar@gmail.com

1 Department of Otorhinolaryngology-Head and Neck Surgery, Okmeydani Training and Research Hospital, Istanbul, Turkey

2 Department of Pediatrics, Okmeydani Training and Research Hospital, Istanbul, Turkey the participants $(p<0.05)$. As a result of the CSHQ evaluation, a statistically significant difference was observed in bedtime resistance, sleep duration, sleep anxiety, night awakening, parasomnia, sleep breathing, daytime sleepiness and the total evaluation after the AT operation. On the other hand, there was no significant difference between pre- and post-op third month responses for delay in falling asleep.

In our study, in terms of sleep habits, a significant improvement was observed in all children regardless of OSA risk. Even if the degree of OSA is mild to moderate, it has a negative effect on sleep quality. These children should be evaluated and operated on for adenotonsillar hypertrophy as in severe OSA.

\section{Compliance with Ethical Standards}

Conflict of Interest None.

\section{References}

1. Kang KT, Chou CH, Weng WC, Lee PL, Hsu WC. Associations between adenotonsillar hypertrophy, age, and obesity in children with obstructive sleep apnea. PLoS One. 2013;8:e78666.

2. Marcus CL, Greene MG, Carroll JL. Blood pressure in children with obstructive sleep apnea. Am J Respir Crit Care Med. 1998;157: 1098-103.

3. Enright PL, Goodwin JL, Sherrill DL, Quan JR, Quan SF; Tucson Children's Assessment of Sleep Apnea Study. Blood pressure elevation associated with sleep-related breathing disorder in a community sample of white and Hispanic children: The Tucson Children's Assessment of Sleep Apnea Study. Arch Pediatr Adolesc Med. 2003;157:901-4.

4. Brouillette RT, Fernbach SK, Hunt CE. Obstructive sleep apnea in infants and children. J Pediatr. 1982;100:31-40.

5. Nieminen P, Löppönen T, Tolonen U, Lanning P, Knip M, Löppönen $\mathrm{H}$. Growth and biochemical markers of growth in children with snoring and obstructive sleep apnea. Pediatrics. 2002;109:e55.

Publisher's Note Springer Nature remains neutral with regard to jurisdictional claims in published maps and institutional affiliations. 